\title{
Effect of microstructure on multifunctional properties of natural fiber composites
}

\author{
Hitoshi Takagi ${ }^{1}$, Antonio Norio Nakagaito ${ }^{2}$, and $\mathrm{Ke} \mathrm{Liu}^{3}$ \\ ${ }^{1}$ Institute of Technology and Science, The University of Tokushima, takagi@tokushima-u.ac.jp \\ ${ }^{2}$ Institute of Technology and Science, The University of Tokushima, \\ nakagaito@tokushima-u.ac.jp \\ ${ }^{3}$ College of Materials and Engineering, Wuhan Textile University, luecole@gmail.com
}

\begin{abstract}
This paper deals with multifunctional properties of natural fiber-reinforced green composites, such as strengthening characteristics, biodegradation behavior and thermal insulating properties. These functionalities are mainly derived from inherent physical and chemical natures of natural fiber used as reinforcement. High-strength green composites can be fabricated by using strong natural fibers such as abaca fiber. The biodegradation speed of the green composites is faster than that of neat biodegradable resin material used as matrix. The enhanced biodegradation properties are attributed to a preferential biodegradation reaction at interfaces between natural fiber and polymer matrix. Better thermal insulation performance is easily attained by using natural fibers with large lumen, which is the hollow middle area in the natural fiber. Therefore the thermal properties of green composites can be easily controlled not only by changing the thermal conductivity values of matrix phase but also by changing the internal microstructure of the reinforcing natural fiber.
\end{abstract}

Keywords: Green composites, Natural fiber, Multifunctionality, Heat insulation, Biodegradation

\section{Introduction}

Natural fiber-reinforced polymer-based composite materials get a great deal of researchers' attention in the fields of packaging, aerospace and automotive industries, because of their varuous advantages; such as low density, high strength properties, biodegradable nature and better thermal properties [1,2]. Therefore, the research and development of environment-friendly composite materials, which have low environmental loads in their disposal stage, are widely carried out [3-9]. Especially, the research attention has been devoted to green composites, which are composed of plant-derived resin and natural fibers, as an alternative material for traditional petroleum-derived polymer composites. Much research on the green composites concerns their mechanical properties; such as tensile properties, flexural properties, and impact properties, on the other hand little research on their functionality has been conducted until now.

Among these enhanced properties, especially, the biodegradation behavior and thermal insulation property of the green composites have been considered as one of the most unique functions. The biodegradable nature of composites leads to the easiness in disposing them after finishing their service life. Additionally, because most of the natural fibers have a hollow microstructure, which is called lumen, there is a strong possibility to obtain the composites having a good thermal insulation property by using such natural fiber. In the last few years, many researchers have been reported on the biodegradability as well as thermal conductivity of various natural fiber composites [10-15]. 
In this study we focus on the functional properties of green composites. To begin with, the enhanced biodegradability of the green composites is described to show their unique biodegradable nature due to the presence of interface between biodegradable resin and natural fiber. Then the thermal insulation properties of green composites are given by evaluating of their thermal conductivity and comparing with other materials including neat resin and conventional glass fiber reinforced plastics (GFRP) and carbon fiber reinforced plastics (CFRP).

\section{Biodegradable properties of natural fiber composites}

The variation of normalized tensile strength of abaca fiber-reinforced starch-based biodegradable green composites (fiber content $=50 \mathrm{wt} \%$ ) and abaca fiber with composting time is shown in Fig. 1 [16]. The initial tensile strength of abaca fiber and green composites were $748 \mathrm{MPa}$ and $254 \mathrm{MPa}$, respectively. It can be seen that both changes in tensile strength show a similar trend. The both tensile strengths rapidly decrease in the initial composting stage (2-5 days). After 5 days compost treatment, the strength gradually declines to less than $20 \%$ of the initial strength level.

Figure 2 shows the variation of weight loss of green composites and neat starch-based resin [16]. The weight loss of both green composites and neat resin rapidly increases after 15 days. In the early stage less than 10 days, the weight loss of both materials shows almost the same value. After 10 days, however the weight loss of green composites becomes larger than that of neat resin. This dependence presumably derived from the increased surface area of composites introduced by the enhanced decomposition both of resin and fiber along the interface between fiber and resin. The surface area of composites decomposed along their interface is presumably much larger than that of neat biodegradable resin, which has relatively flat surface. In addition the preferential water transportation may be achieved through internal cavity within natural fiber.

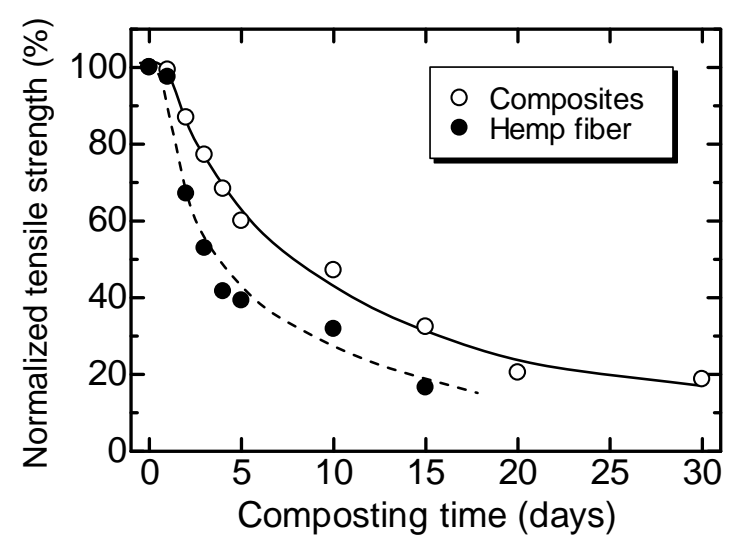

Figure 1: Variation of normalized tensile strength

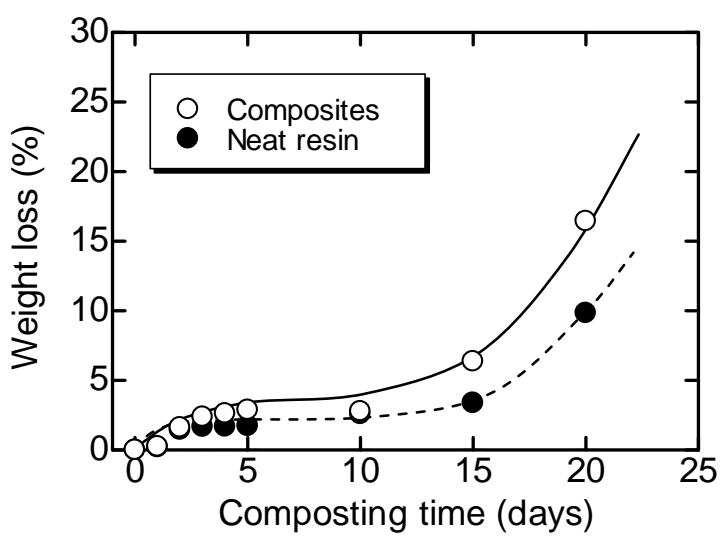

Figure 2: Variation of weight loss

\section{Thermal insulation properties of natural fiber composites}

Figure 3 shows variation of thermal conductivity for polylactic acid (PLA)-bamboo green composites containing 60wt.\% bamboo fiber. The thermal conductivity data for zero density corresponds to thermal conductivity of air $(0.026 \mathrm{~W} /(\mathrm{m} \bullet \mathrm{K}))$. The

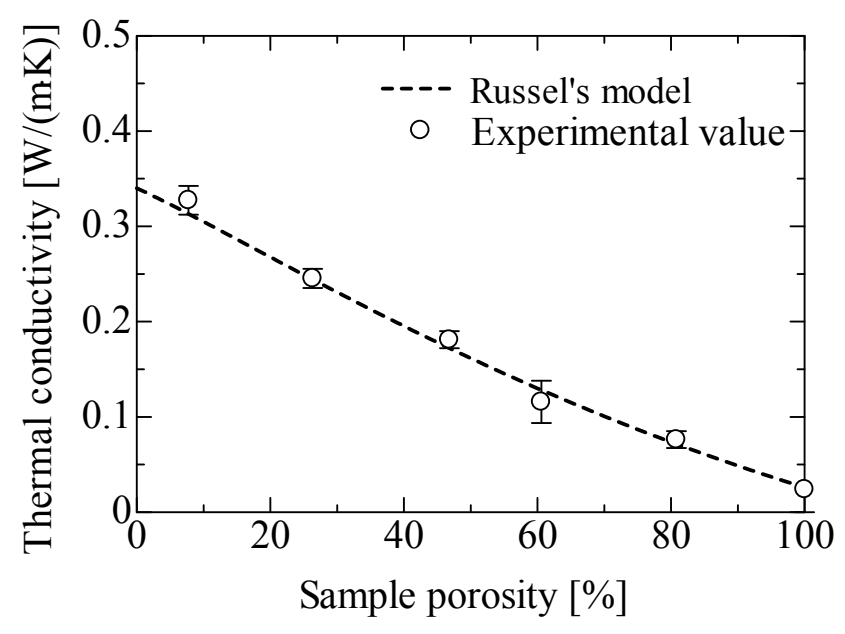

Figure 3: Variation of thermal conductivity

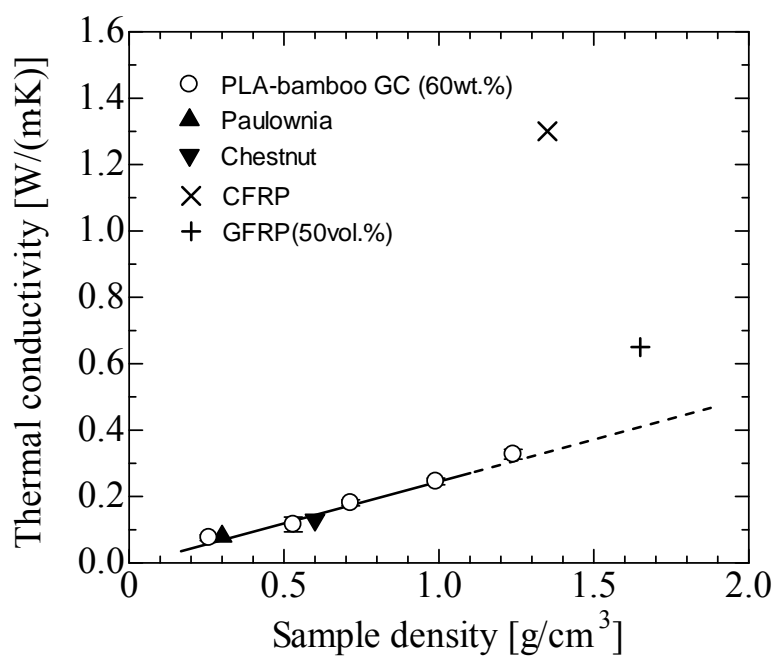

Figure 4: Thermal conductivity of various materials 
thermal conductivity of PLA-bamboo green composites almost linearly increases with increasing sample density in the same manner as conventional heat insulating materials such as glass wool and rock wool [15]. A theoretically estimated thermal conductivity values for two-phase composite material containing many voids are calculated from Russell's model [17]. The fitted value of the thermal conductivity of solid phase, $\lambda \mathrm{s}$ is $0.340 \mathrm{~W} /(\mathrm{m} \cdot \mathrm{K})$, and this value is much greater than thermal conductivity of PLA neat resin $(0.20 \mathrm{~W} /(\mathrm{m} \cdot \mathrm{K}))$ and therefore the thermal conductivity of bamboo fiber is estimated to be larger than $0.340 \mathrm{~W} /(\mathrm{m} \cdot \mathrm{K}))$.

Figure 4 demonstrates the relationship between thermal conductivity and density for various materials including woods and FRPs. It can be seen that thermal conductivity of PLA-bamboo green composites is smaller than that of GFRP and CFRP. It should be noted that the PLA-bamboo green composites have very low thermal conductivity, which is almost the same value of natural woods.

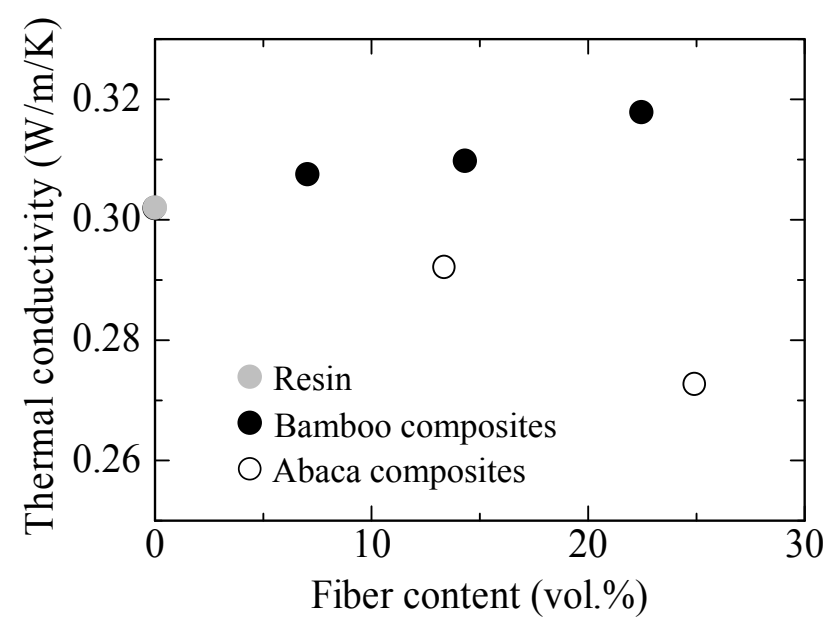

Figure 5: Variation of thermal conductivity of bamboo and abaca composites

Figure 5 shows the relationship between thermal conductivity of bamboo composites and abaca composites and fiber content [18]. It can be seen that thermal conductivity of abaca composites decreases with increasing fiber content. The decreasing tendency of abaca composites could be attributed to the fact that abaca fiber has relatively large lumen, therefore air content in composites also increases with increasing fiber content and that the thermal conductivity of air is much smaller than that of the fiber. In the case of GFRP, conventional glass fiber is usually solid and has relatively high thermal conductivity, thus GFRP has relatively high thermal conductivity compared with that of matrix resin, and the thermal conductivity value increases with increasing fiber content. Hence it is difficult for GFRP to have high strength and low thermal conductivity. However it should be noted that in the case of green composites reinforced by strong natural fiber with large lumen, it is easy to realize such a situation; namely high strength and low thermal conductivity.

\section{Conclusion}

Absolute mechanical properties of green composites are inferior to those of GFRP and CFRP, however the green composites have variety of functional properties; such as biodegradability and heat insulation property. The use of natural fibers as an environment-friendly reinforcing phase means not only an improvement in sustainability in the point of raw materials, but also the enhancement in physical performances as well as multi-functionalities.

\section{Acknowledgement}

This work was financially supported by Japan Society for the Promotion of Science (JSPS) KAKENHI Grant Number 25289243.

\section{References}

1. K. Okubo, H. Takagi, and K. Goda, J. Soc. Mat. Sci., Japan, 55 (2006) 438-44.

2. S. Thomas and L. A. Pothan, Natural fibre reinforced polymer composites, Old City Publishing, Inc., Philadelphia (2009).

3. M. Wollerdorfer and H. Bader, Industrial Crops and Products, 8 (1998) 105-12.

4. S. Luo and A. N. Netravali, Journal of Materials Science, 34 (1999) 3709-19. 
5. S. Luo and A. N. Netravali, Polymer Composites, 20 (1999) 367-78.

6. P. Lodha and A. N. Netravali, Journal of Materials Science, 37 (2002) 3657-65.

7. A. N. Netravali and S. Chabba, Composites get greener, Materialstoday, April, (2003) 22-8.

8. A. K. Mohanty, M. Misra and G. Hinrichsen, Macromolecular Materials and Engineering, 276/277 (2000) 1-24.

9. D. H. Mueller and A. Krobjilowski, Journal of Industrial Textiles, 33 (2003) 111-30.

10. S. Ochi and H. Takagi, J. Soc. Mat. Sci., Japan, 53 (2004) 434-58.

11.N. Teramoto, K. Urata, K. Ozawa, and M. Shibata, Polymer Degradation and Stability, 86 (2004) 401-9.

12. R. Agrawal, N. S. Saxena, M. S. Sreekala, and S. Thomas, J. Polym. Sci. Pol. Phys., 38 (2000) 916-21.

13. R. Mangal, N. S. Saxena, M. S. Sreekala, and S. Thomas, Mat. Sci. Eng. A-Struct., 339 (2003) 281-5.

14. S. W. Kim, S. H. Lee, J. S. Kang, and K. H. Kang, Int. J. Thermophys., 27 (2006) 1873-81.

15. H. Takagi, S. Kako, K. Kusano, and A. Ousaka, Adv. Compos. Mater., 16 (2007) 377-84.

16. H. Takagi, Advanced Materials Research, 123-125 (2010) 1163-6

17. H. W. Russell, Journal of American Ceramic Society, 18 (1935) 1-5.

18. H. Takagi, K. Liu, R. Osugi, A. N. Nakagaito, and Z. Yang, Journal of Biobased Materials and Bioenergy, 6 (2012) 470-4.. 